\title{
In silico docking of methyl isocyanate (MIC) and its hydrolytic product (1,3-dimethylurea) shows significant interaction with DNA Methyltransferase 1 suggests cancer risk in Bhopal-Gas- Tragedy survivors
}

\author{
Inbesat Khan ${ }^{1 *}$, Chinnu Sugavanam Senthilkumar ${ }^{2}$, Nisha Upadhyay ${ }^{1}$, Hemant \\ Singh $^{1}$, Meenu Sachdeva ${ }^{1}$, Suresh Kumar Jatawa ${ }^{1}$, Archana Tiwari ${ }^{1}$
}

\begin{abstract}
DNA methyltransferase 1 (DNMT1) is a relatively large protein family responsible for maintenance of normal methylation, cell growth and survival in mammals. Toxic industrial chemical exposure associated methylation misregulation has been shown to have epigenetic influence. Such misregulation could effectively contribute to cancer development and progression. Methyl isocyanate (MIC) is a noxious industrial chemical used extensively in the production of carbamate pesticides. We here applied an in silico molecular docking approach to study the interaction of MIC with diverse domains of DNMT1, to predict cancer risk in the Bhopal population exposed to MIC during 1984. For the first time, we investigated the interaction of MIC and its hydrolytic product (1,3-dimethylurea) with DNMT1 interacting (such as DMAP1, RFTS, and CXXC) and catalytic (SAM, SAH, and Sinefungin) domains using computer simulations. The results of the present study showed a potential interaction of MIC and 1,3-dimethylurea with these domains. Obviously, strong binding of MIC with DNMT1 interrupting normal methylation will lead to epigenetic alterations in the exposed humans. We suggest therefore that the MICexposed individuals surviving after 1984 disaster have excess risk of cancer, which can be attributed to alterations in their epigenome. Our findings will help in better understanding the underlying epigenetic mechanisms in humans exposed to MIC.
\end{abstract}

Keywords: Molecular docking - in silico interaction - methyl isocyanate (MIC) - 1,3-dimethylurea - DNMT1

Asian Pac J Cancer Prev, 16 (17), 7663-7670

\section{Introduction}

There is increasing evidence that exposure to toxic chemicals primarily affect the epigenome leading to the alteration of normal epigenetic process (Hou et al., 2011), In humans, chemically-induced epigenetic alterations has been reported to play an important role in cancer development and progression (Fraga et al., 2005; Baccarelli and Bollati, 2009; Shrivastava et al., 2013). Methyl isocyanate (MIC) is a toxic chemical used as an intermediate in the production of carbamate pesticides (HSFS, 2002; Senthilkumar et al., 2011; 2012; 2013). Accidental leakage of MIC from storage tank number E610 of Bhopal Union Carbide India Limited (UCIL) pesticide production plant on 3rd December, 1984 resulted in the mortality of 3600 inhabitants and about 2,00,000 were severely exposed. This catastrophe was caused by the introduction of water with 40 tonnes of MIC.Analysis conducted after Bhopal episode have concluded the presence of several toxic chemicals residues, including 1,3-dimethylurea in E610. MIC reacts exothermically with water to form carbon dioxide, methylamine, dimethylurea and/or trimethylbiuret (Stringer et al., 2002; NOAAS, 2015).

Exposure to MIC causes several respiratory disorders and chronic obstructive pulmonary disease (COPD) (Vandenplas et al., 1993; Baur et al., 1994; De, 2012; 2013). Besides, the immunotoxic (Karol et al., 1987), genotoxic (Conner et al., 1987; Tice et al., 1987), reproductive and developmental toxic effects (Schwetz et al., 1987) are well-documented in humans and animals. However, the etiology of MIC in carcinogenesis is far from completely understood (Senthilkumar et al., 2012; Senthilkumar, 2012). Data from animal studies have shown that the carcinogenic potency of MIC is low and weak (Gassert et al., 1986; Ennever and Rosenkranz, 1987; Bucher and Uraih, 1989). Evidence from in vitro studies suggest MIC-induced oncogenic transformation

${ }^{1}$ School of Biotechnology, Rajiv Gandhi Technological University, ${ }^{2}$ Clinical Cytogenetics Laboratory, Department of Research, Jawaharlal Nehru Cancer Hospital \& Research Centre, Bhopal, India *For correspondence: Inbesat.Epig@gmail.com 
Inbesat Khan et al

in human cells (Mishra et al., 2009abc; Raghuram et al., 2010; Hariom and Mishra, 2011; Hariom et al., 2011). But still, toxic chemical substances analyzing agencies are categorizing MIC as a non-carcinogenic substance (Senthilkumar et al., 2012).

Almost three decades elapsed of Bhopal disaster, only a few efforts have been made to understand the cancer risk in the MIC-exposed survivors (Malla et al., 2011; Senthilkumar et al., 2011; 2012; 2015). Emerging epidemiological reports from Bhopal, India suggest diverse cancer pattern amongst the MIC-gas exposed survivors (Dikshit and Kanhere, 1999; Ganesh et al., 2005; Senthilkumar et al., 2011). It was therefore, worthwhile to investigate the underlying mechanisms of MIC on epigenetic alterations/DNA methylation using computational methods. In the present study, we aimed to understand the in silico interaction of MIC and its hydrolytic product (1,3-dimethylurea) with DNA methyltransferase (DNMT) domains, in order to reveal the cause for cancer risk in Bhopal population exposed to MIC during 1984.
DNA methylation is essential for the maintenance of normal epigenetic process (Miller et al., 1974). Aberrant methylation is the major cause of several cancers, shows both hyper- and hypo-methylation patterns (Robertson, 2005). Hypermethylation of tumor suppressor genes

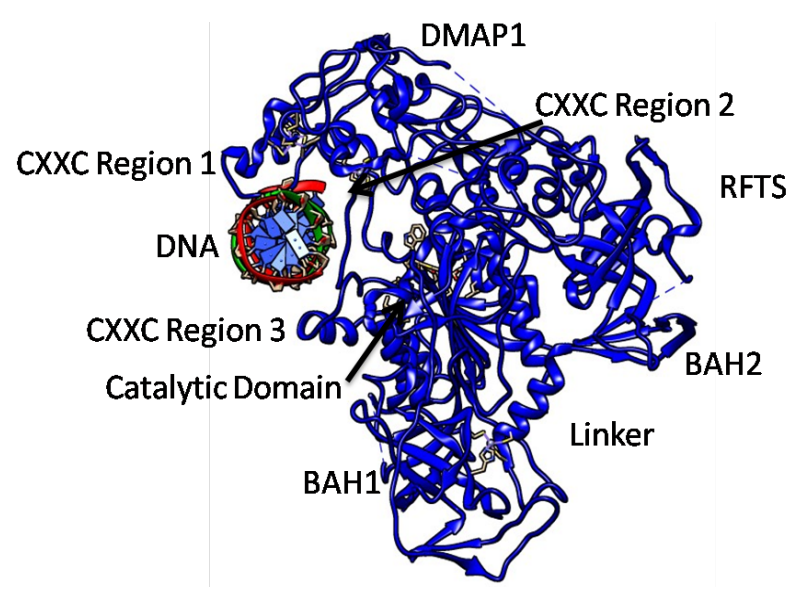

Figure 1. DNMT1 and its Diverse Interacting Domains

Table 1. Detailed Interaction Profiles of MIC and 1,3-Diurea with DNA binding CXXC (1 - 3), DMAP1, RFTS Region (1 and 2), catalytic SAH/SAM and Sinefungin site

\begin{tabular}{|c|c|c|c|c|c|c|c|c|c|}
\hline Ligand & $\begin{array}{c}\text { Docking } \\
\text { Score }\end{array}$ & $\begin{array}{c}\mathrm{XP} \\
\text { Score }\end{array}$ & $\begin{array}{l}\text { Glide } \\
\text { Score }\end{array}$ & $\begin{array}{c}\text { Glide } \\
\text { E-Model }\end{array}$ & H- Bonding & $\begin{array}{l}\text { Length of } \\
\text { H Bond }(\AA)\end{array}$ & $\begin{array}{c}\text { Acceptor } \\
\text { Angle }\end{array}$ & $\begin{array}{l}\text { Donor } \\
\text { Angle }\end{array}$ & $\begin{array}{l}\text { Bonded } \\
\text { Chain }\end{array}$ \\
\hline \multicolumn{10}{|c|}{ DNA Binding CXXC Region 1} \\
\hline 1,3-Dimethylurea & -2.738 & -2.738 & -2.738 & -20.394 & Glycine (684) & $\begin{array}{l}2.18(\mathrm{H}) \\
2.15(\mathrm{H})\end{array}$ & $\begin{array}{l}151.653 \\
155.159\end{array}$ & $\begin{array}{l}121.953 \\
141.501\end{array}$ & Backbone \\
\hline MIC & -1.852 & -1.852 & -1.852 & -9.714 & Lysine (683) & $1.96(\mathrm{O})$ & - & 133.694 & Backbone \\
\hline \multicolumn{10}{|c|}{ DNA Binding CXXC Region 2} \\
\hline 1,3-Dimethylurea & -2.237 & -2.237 & -2.237 & -15.402 & Cystine (686) & $\begin{array}{l}2.21(\mathrm{H}) \\
2.25(\mathrm{H})\end{array}$ & $\begin{array}{l}157.022 \\
155.57\end{array}$ & $\begin{array}{c}90.87 \\
141.668\end{array}$ & Backbone \\
\hline $\begin{array}{l}\text { MIC } \\
\text { DNA Binding } C X X\end{array}$ & $\begin{array}{l}-1.223 \\
\text { Region } 3\end{array}$ & -1.223 & -1.223 & -8.239 & Arginine (690) & $2.30(\mathrm{O})$ & - & 98.767 & Side Chain \\
\hline 1,3-Dimethylurea & -2.808 & -2.808 & -2.808 & -17.272 & $\begin{array}{l}\text { Methionine (696) } \\
\text { Glutamic Acid (698) }\end{array}$ & $\begin{array}{l}2.05(\mathrm{O}) \\
1.86(\mathrm{H})\end{array}$ & $\begin{array}{c}- \\
160.345\end{array}$ & $\begin{array}{l}157.33 \\
155.454\end{array}$ & $\begin{array}{l}\text { Backbone } \\
\text { Side Chain }\end{array}$ \\
\hline MIC & -2.02 & -2.02 & -2.02 & -9.414 & $\begin{array}{l}\text { Arginine (1574) } \\
\text { Glutamic Acid (698) }\end{array}$ & $\begin{array}{l}2.09(\mathrm{O}) \\
2.09(\mathrm{O})\end{array}$ & $\begin{array}{l}- \\
-\end{array}$ & $\begin{array}{c}94.92 \\
163.858\end{array}$ & $\begin{array}{l}\text { Side Chain } \\
\text { Side Chain }\end{array}$ \\
\hline \multicolumn{10}{|c|}{ DNMT1 Associated Protein 1} \\
\hline 1,3-Dimethylurea & -2.205 & -2.205 & -2.205 & -14.916 & Asparginine (1379) & $\begin{array}{l}2.03(\mathrm{H}) \\
1.94(\mathrm{O})\end{array}$ & $\begin{array}{c}152.599 \\
-\end{array}$ & $\begin{array}{l}140.665 \\
102.877\end{array}$ & $\begin{array}{l}\text { Backbone } \\
\text { Side Chain }\end{array}$ \\
\hline MIC & -1.752 & -1.752 & -1.752 & -9.335 & Aspartic Acid (1416) & 6) $2.07(\mathrm{O})$ & - & 121.712 & Backbone \\
\hline \multicolumn{10}{|c|}{ Replication Focii Targeting Sequence Domain Region 1} \\
\hline 1,3-Dimethylurea & -2.977 & -2.977 & -2.977 & -16.621 & $\begin{array}{l}\text { Phenylalanine }(483) \\
\text { Proline (403) }\end{array}$ & $\begin{array}{l}2.37(\mathrm{H}) \\
1.72(\mathrm{H})\end{array}$ & $\begin{array}{l}143.35 \\
166.236\end{array}$ & $\begin{array}{l}121.327 \\
124.141\end{array}$ & $\begin{array}{l}\text { Backbone } \\
\text { Backbone }\end{array}$ \\
\hline MIC & -1.783 & -1.783 & -1.783 & -6.432 & $\begin{array}{l}\text { Threonine (467) } \\
\text { Glycine (468) }\end{array}$ & $\begin{array}{l}2.33(\mathrm{~N}) \\
2.03(\mathrm{O})\end{array}$ & $\begin{array}{l}- \\
-\end{array}$ & $\begin{array}{r}98.906 \\
156.032\end{array}$ & $\begin{array}{l}\text { Side Chain } \\
\text { Backbone }\end{array}$ \\
\hline \multicolumn{10}{|c|}{ Replication Focii Targeting Sequence Domain Region 2} \\
\hline 1,3-Dimethylurea & -2.702 & -2.702 & -2.702 & -19.087 & $\begin{array}{l}\text { Lysine (350) } \\
\text { Phenylalanine(469) }\end{array}$ & $\begin{array}{l}1.95(\mathrm{O}) \\
2.00(\mathrm{H})\end{array}$ & 162.454 & $\begin{array}{l}132.93 \\
141.914\end{array}$ & $\begin{array}{l}\text { Side Chain } \\
\text { Backbone }\end{array}$ \\
\hline MIC & -1.772 & -1.772 & -1.772 & -9.422 & No Bound Residue & - & - & - & - \\
\hline \multicolumn{10}{|c|}{ Catalytic Methyltransferase Domain (SAH/SAM) } \\
\hline 1,3-Dimethylurea & -3.182 & -3.182 & -3.182 & -27.699 & $\begin{array}{l}\text { Valine }(1580) \\
\text { Leucine }(1151)\end{array}$ & $\begin{array}{l}2.07(\mathrm{O}) \\
2.17(\mathrm{O})\end{array}$ & $\begin{array}{l}- \\
-\end{array}$ & $\begin{array}{l}144.91 \\
111.548\end{array}$ & $\begin{array}{l}\text { Backbone } \\
\text { Backbone }\end{array}$ \\
\hline MIC & -2.729 & -2.729 & -2.729 & -13.559 & $\begin{array}{l}\text { Methionine (1169) } \\
\text { Cystine (1191) }\end{array}$ & $\begin{array}{l}2.24(\mathrm{O}) \\
2.07(\mathrm{~N})\end{array}$ & $\begin{array}{l}- \\
-\end{array}$ & $\begin{array}{r}95.662 \\
100.039\end{array}$ & $\begin{array}{l}\text { Backbone } \\
\text { Backbone }\end{array}$ \\
\hline \multicolumn{10}{|c|}{ Catalytic Methyltransferase Domain (Inhibhitor-Sinefungin) } \\
\hline 1,3-Dimethylurea & -3.086 & -3.086 & -3.086 & -28.544 & $\begin{array}{l}\text { Valine }(1576) \\
\text { Leucine }(1151) \\
\text { Serine }(1146)\end{array}$ & $\begin{array}{l}1.73(\mathrm{O}) \\
2.24(\mathrm{O}) \\
2.30(\mathrm{H}) \\
2.47(\mathrm{H})\end{array}$ & $\begin{array}{c}- \\
- \\
125.269 \\
124.269\end{array}$ & $\begin{array}{r}128.092 \\
102.162 \\
112.212 \\
94.759\end{array}$ & $\begin{array}{l}\text { Backbone } \\
\text { Backbone } \\
\text { Backbone } \\
\text { Backbone }\end{array}$ \\
\hline MIC & -2.286 & -2.286 & -2.286 & -10.899 & Cystine (1191) & $2.39(\mathrm{O})$ & - & 120.133 & Backbone \\
\hline
\end{tabular}


contributes to oncogenesis (Dante et al., 1991; Jones and Martienssen, 2005). Global hypomethylation also results in genome wide instability that leads to oncogenesis (Guo et al., 2014).

DNA Methyl Transferase (DNMT) is relatively large protein family that controls methylation and responsible for cell growth and its survival in mammals (Qin et al., 2011). Knockout of any regions of DNMT results in the aberrant development that causes cell death ( $\mathrm{Li}$ et al., 1992; Okano et al., 1999). DNMT1 is abundantly found in the cell and maintains the methylation process during replication (Leonhardt et al., 1992). DNMT1 holds 1616 amino acids with $\mathrm{N}$-terminal and C-terminal catalytic regions, linked together by seven lysyl-glycyl dipeptide repeats referred to as $(\mathrm{KG}) 7$ linker (Jurkowska et al., 2011). N-terminal region contains DNA methyl transferase associated protein 1 (DMAP1) interacting domain, proliferating cell nuclear antigen (PCNA) binding domain, nuclear localization signal (NLS), targeting sequence (TS) / Replication Foci Targeting Sequence (RFTS) domain, CXXC (Zinc Finger) domain, tandem bromo-adjacent homology (BAH) 1 and 2, and KG linker. $\mathrm{N}$-terminal domain controls the activity of catalytic domain. The catalytic domain of DNMT1 forms a core complex that makes contact with the single side of DNA. DNMT 3a and $\mathrm{b}$ are involved in de novo methylation (Mortusewicz et al., 2005; Chen and Li, 2006). Recent studies have shown a significant association of DNMT3 in the maintenance of methylation and DNMT1 in de novo methylation (Jeltsch and Jurkowska, 2014). C-terminal region comprise a catalytic domain with different regions viz. I, IV, VI, and VIII-X, altogether constitutes methyl transferase motifs that helps in methyl group transfer from S-Adenosyl Methionine (SAM) to methyl cytosine through specialized base flipping mechanism (Jurkowska et al., 2011; Paganon et al., 2011; Clements et al., 2012). S-adenosyl homocysteine (SAH) (AdoHcy) is located at the active center of catalytic domain. CXXC-BAH1 domains are situated on different sides of the catalytic domain and connected by its long linker. BAH1 and BAH2 domains are located distantly from the bound DNA and separated from each other by $\alpha$-helical linker (Figure 1) (Song et al., 2012).

Therefore, we studied the interaction of (DMAP1, RFTS, and CXXC) and catalytic (SAM, SAH, and Sinefungin) domains of DNMT1 using MIC and 1, 3-Dimethylurea as ligands. We used Schrödinger GLIDE as molecular docking tool.

\section{Materials and Methods}

\section{Source, selection and preparation of protein}

A total of four human DNMT1 proteins (viz. DMAP1, RFTS, DNMT1 in complex with DNA, and Sinefungin) and their three-dimensional (3-D) crystal structures were retrieved from the Protein Data Bank (PDB, 2014a-d) (ID: 4IEJ, 3EPZ, 3PTA, 3SWR) by X-Ray diffraction with the resolution range from 1.45 to $3.60 \AA$. The raw crystal structures were subjected to docking preparation using Protein Preparation Wizard (PPW). These raw crystal structures were scrutinized for excessive heavy atoms, improper bonding, missing of side chains, presence of co-crystallized ligand, water molecules, metal ions, and cofactors etc. Using PPW, hydrogen and appropriate bonds were added to the structures. Metals were treated by breaking bonds and assigned with formal charges. Disulfide bonds were added between two adjacent sulphur molecules. Overlaps were removed, water molecules were deleted, and missing loops were filled using the PRIME. $\mathrm{N}$-Acetyl (ACE) and N-Methyl Amide (NMA) groups were added to uncap the $\mathrm{N}$ - and $\mathrm{C}$-terminus. In addition, the hetro-groups were also detached. Protonation and metal charges states were generated. Hydrogen bonds were optimized using the PROT ASSIGN. Finally, the protein structure was subjected to restrained minimization in the Impref utility using the OPLS2005 force field. (Jacobson et al., 2004; Shelley et al., 2007; Shivakumar et al., 2010; Sastry et al., 2013).

\section{Preparation of ligand}

3-D ligand structures of MIC and 1,3-dimethylurea were retrieved from ZINC Database (Irwin and Shoichet, 2005). Ligand geometry was optimized by generating the structural variants, which reduced the structural problems in ligands and these structures were checked through LIGPREP. Ionization state was generated in the default $\mathrm{pH} 7.0 \pm 2.0$ using ionizer. The structure was desalted to retain molecule with the largest number of atoms. Tautomers were generated for each neutralized/ionized molecule. Finally, around 32 stereoisomers were created with retained specific chiralities according to Greenwood et al. (2010).

\section{Generation of receptor grid}

The receptor grid is a 3-D boundary for ligand binding. The grid was generated specifically for various domains of the proteins. The residues of DMAP1 interacting with DNMT1 was determined using the structure (PDB ID: 4IEJ). The grid was created on the centroid region of selected residues in which DMAP1 and DNMT1 interact, in order to confine the ligands to that specific region during the docking process. Similarly, CXXC region interacting with DNA was analyzed using the structure (PDB ID: 3PTA) and grids were generated separately in three regions. RFTS Domain (PDB ID: 3EPZ) was also analyzed using the same procedure and the grid was generated for two different regions of DNMT1, where the interaction with replication foci occurs. With reference to catalytic domain of DNMT1, SAH is previously co-crystallized with the structure (PDB ID: 3PTA) and therefore the grid generation process was totally different. The grid was generated at the centroid of selected ligand with co-crystallized SAH. The grid was generated around this ligand and grid file also lack this ligand. Typically, using this procedure the grid was generated and ligands were docked only for this region. Similar procedure was adapted for Sinefungin (PDB ID: 3SWR). Van Der Waals scaling was made for all the grids using default scaling factor of 1.0 and partial cut-off charges were 0.25 as described earlier (Friesner et al., 2004). 

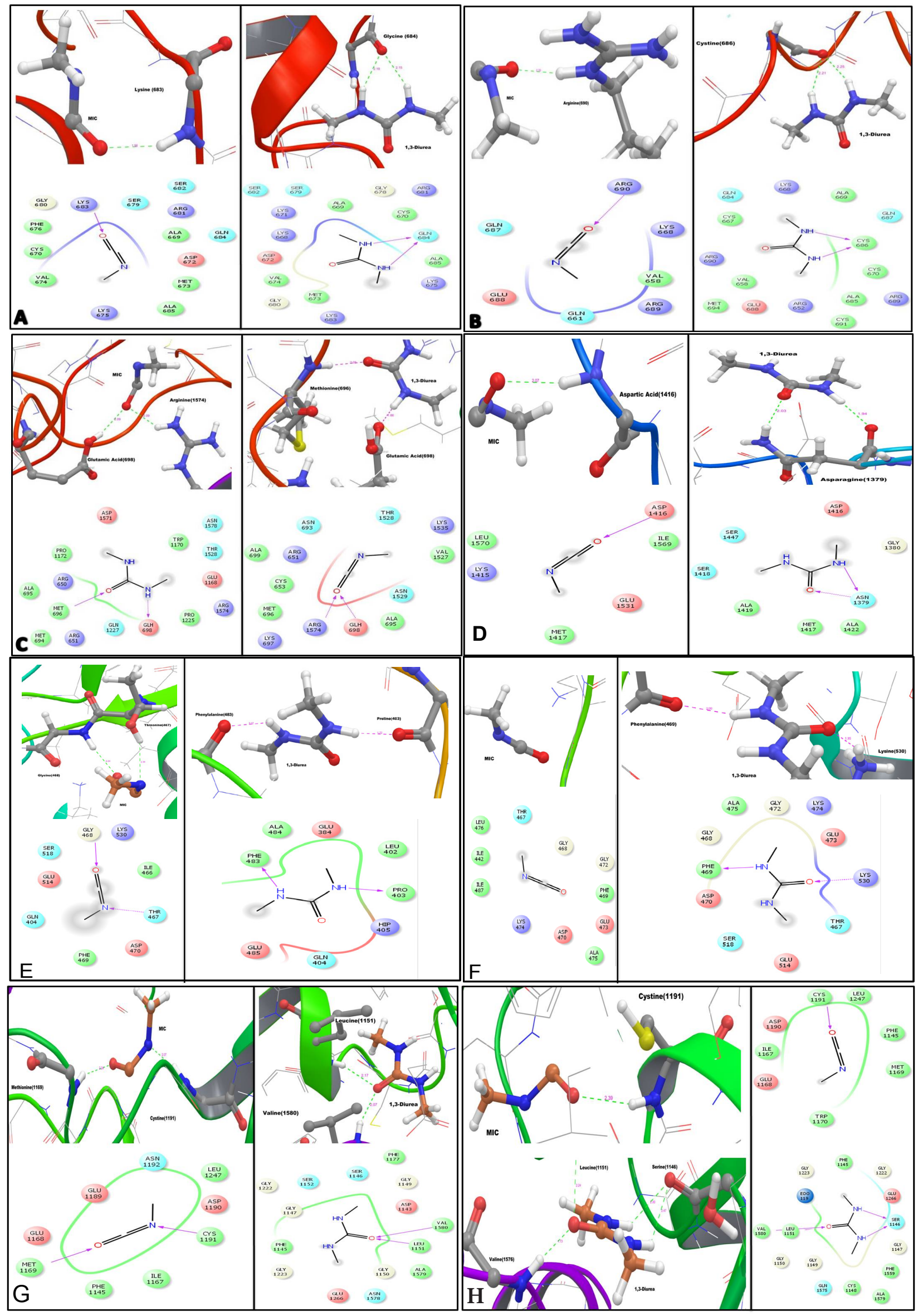

Figure 2. Docked Position of CXXC Domain (A - Region 1, B - Region 2, and C - Region 3), DMAP1 (D), RFTS (E-Region 1 and F - Region 2), SAH/SAM (G), and Sinefungin Binding Domain (H) of DNMT1 with Ligands. Structural view of hydrogen bond (green dashed line) showing the distance, where as the ligand interaction (solid pink arrows) represents electrostatic relations (H-Bond) with main backbone of protein and side chain (dashed pink line ) 


\section{In silico docking}

The docking sites for ligand were presented by grids. During the docking procedure of Schrodinger GLIDE, the ligands and grids were assessed and then subjected to induced fit flexible docking using Extra Precision (XP) mode. While docking the protein, the receptor was rigid, but the ligand was flexible. Van Der Waals radii scaling were done with the default scaling factor 0.8 and a partial charge cut-off as 0.15 . Different conformations were created internally by GLIDE and subjected through a set of filters, viz. Euler angles, grid based force field evaluation and refinement, and Monte Carlo energy minimization according to Friesner et al. (2006). Finally, the docked conformers were estimated using GLIDE score and a single best position per ligand was generated as an output as described earlier (Halgren et al., 2004). For each ligand and protein site, the docked positions were determined accordingly to the docking profile (such as docking, XP GLIDE, and standard precision GLIDE scores). In addition, GLIDE-E model was calculated and it is directly proportional to the elevated negative value i.e. increased negative value is considered as a better docking score. This score is the measure of strength and stability of the bound-ligand-protein.

\section{Results}

Table 1 depicts the docking profile of MIC and 1,3-dimethylurea with DNMT1 (Figure 2A-H). Both the ligands showed significant interaction with amino acids and stable hydrogen bond formation with core- and sidechains on various regions of DNMT1. Hydrogen bonds formed by ligands with the protein residue were found between 1.5 to $2.5 \AA$. The minimum donor and acceptor angle is $120^{\circ}$ and $90^{\circ}$, respectively. 1,3-dimethylurea has shown a strong interaction as compared to MIC. This interaction is due to the size and complexity of the molecule. Besides, the strongest binding was observed for $\mathrm{SAH}$ and Sinefungin region (Figure $2 \mathrm{G}$ and $\mathrm{H}$ ).

\section{Discussion and Conclusion}

In silico docking reveals the effect of any chemicals and its binding affinity on 3-D conformational structures (Khamkar et al., 2013). With the use of computational methods, numerous studies have discovered that several cancers are markedly triggered by epigenetic alterations (Mahdavi et al., 2012; Wu et al., 2013; Jiang et al., 2014; Song et al., 2014; Zhuo e t al., 2014; Wang et al., 2015; Wang and Yan, 2015). The present study was also an attempt to determine the in silico interaction of MIC and 1,3-dimethylurea with several domains of DNMT1.

DMAP1 is a charge rich region that binds with MIC and 1,3-dimethylurea specifically interferes as a transcriptional repressor in the normal process. Interference of the repressive activity results in the aberrant expression of genes (Rountree et al., 2000). Furthermore, any impendence in the normal binding of DMAP1 to DNA at CpG sites may exhibit a lack of DNMT1 activity, which affects the gene expression (Bashtrykov et al., 2012). Besides, DMAP1 also form several complexes that participate in the replication process. DNMT1-DMAP1 complex is recruited in the replication foci during S-phase that facilitates the replication and also provides stability to DNMT1-histone deacetylase (HDAC) activity. Therefore, the binding of MIC and 1,3-dimethylurea with DMAP1 apparently hinders the normal methylation process that cause malfunction of transcription machinery (Rountree et al., 2000).

CXXC domain is a crescent shaped $\mathrm{ZN}+$ binding domain, rich in cystine and contains 8 catalytically important cystine residues in the form CXXC motif. CXXC binds to CpG of DNA at both major- and minorgrooves and also links to the bases and phosphate groups (Pradhan et al., 2008; Risner et al., 2013). In the present study, we noticed the binding of both the ligands with various regions of CXXC, which may affects the normal methylation mechanism. RFTS domain targets DNMT1 in the Replication Foci during S-phase. Besides, it also induces DNMT1 to heterochromatin region from late S-phase to early G1-phase of the cell cycle. Therefore, the ligands interacting with RFTS may influence the DNA replication and cell cycle (Paganon et al., 2011). RFTS also contains $\mathrm{Zn}+$ binding motifs, where its hydrophobic interactions cause dimerization of DNMT1. Ligand binding to RFTS inhibits the interaction, which results in to aberrant methylation process (Clements et al., 2012).

SAM (Adomet) is considered as a key methyl donor in almost every methylation reactions of the cell. SAM is produced by single carbon metabolism network with the help of dietary folates (Lu, 2000). SAM acts a cofactor of DNMT1 and binds to its catalytic domain, which triggers the methylation reaction. During this process, the cytosine is flipped out from the DNA double helix, where the formation of covalent enzyme-substrate intermediates occurs as a result with the transfer of methyl group to the cytosine (Song et al., 2012). Thereafter, Adomet is converted into SAM, which is a potent inhibitor of methylation reactions (Finkelstein, 1990; Hermann et al., 2004). Both the MIC and 1,3-dimethylurea was found to bind strongly with this region, indicated the transfer of SAM-SAH may affect the normal methylation reaction.

Sinefungin, an antibiotic obtained from Streptomyces griseolus is an inhibitor of DNMT1. It acts antagonistically to SAM by blocking the methyl transfer reactions. Sinefungin binds strongly than SAM and SAH. Therefore, it is well-known to inhibit DNMT1 (Schluckebier et al., 1997; Kilgore et al., 2013). Both the ligands have shown significant interaction with this region, where as Sinefungin acted as an inhibitor. The preoccupied condition of MIC and 1,3-dimethylurea cause obstruction in the normal inhibitory mechanism of Sinefungin.

In agreement to our results, several studies proved that the global hypomethylation is due to many environmental and agricultural chemicals (Hou et al., 2011) have plausible role in cancer etiology. Interestingly, recent docking studies conducted by Shrivastava et al. (2010; 2013) and Tripathi et al. (2015) also demonstrated a comprehensive understanding of MIC with different immunoproteins against Tuberculosis. To support our findings, recent epidemiological and experimental studies also indicate genetic instability in the MIC-exposed 
survivors, are highly susceptible to cancers (Malla et al., 2011; Senthilkumar et al., 2011; 2013; 2015). Almost 30 years elapsed after Bhopal disaster, owing to several bias and factors it is difficult to understand the direct or indirect effects of MIC in the exposed survivors. Hence, this kind of in silico docking analysis will be helpful to elucidate the underlying disease mechanism in the MIC-exposed survivors and their epigenetic status. To our knowledge, this is the first study to report the interaction of MIC and 1,3-dimethylurea with DNMT1 (DMAP1, RFTS, and CXXC) and catalytic (SAM/SAH and Sinefungin) domains.

In summary, we found a potential interaction of MIC and 1,3-dimethylurea with these domains. Apparently, the stronger binding of MIC with DNMT1 interrupts the normal methylation will lead to epigenetic alterations in the exposed survivors. We conclude therefore that the MIC-exposed individuals surviving after 1984 disaster have excess risk of cancer, which can be attributed to alterations in their epigenome. Our findings will help in better understanding the underlying epigenetic mechanisms in humans exposed to MIC.

\section{References}

Baccarelli A, Bollati V (2009). Epigenetics and environmental chemicals. Current Opinion Pedia, 21, 243.

Bashtrykov P, Jankevicius G, Smarandache A, et al (2012). Specificity of Dnmt1 for methylation of hemimethylated $\mathrm{CpG}$ sites resides in its catalytic domain. Chemistry \& Biol, 19, 572-8.

Baur X, Marek W, Ammon J, et al (1994). Respiratory and other hazards of isocyanates. Int Arch Occ Env health, 66, 141-152.

Bezek Š, Ujhazy E, Mach M, et al (2008). Developmental origin of chronic diseases: toxicological implication. Interdiscipli Toxicol, 1, 29-31.

Bucher JR, Uraih L (1989). Carcinogenicity and pulmonary pathology associated with a single 2-hour inhalation exposure of laboratory rodents to methyl isocyanate. $\mathrm{J} \mathrm{Nat}$ Cancer Inst, 81, 1586-7.

Chen T, Li E (2006). Establishment and maintenance of DNA methylation patterns in mammals. DNA Methylation: Basic Mechanisms. Springer, 179-201.

Clements EG, Mohammad HP, Leadem BR, et al (2012). DNMT1 modulates gene expression without its catalytic activity partially through its interactions with histonemodifying enzymes. Nucleic Acids Res, 40, 4334-46.

Conner M, Rubinson H, Ferguson J, et al (1987). Evaluation of sister chromatid exchange and cytotoxicity in murine tissues in vivo and lymphocytes in vitro following methyl isocyanate exposure. Environ Health Perspectives, 72, 177.

Dante R, Dante-Paire J, Rigal D, et al (1991). Methylation patterns of long interspersed repeated DNA and alphoid repetitive DNA from human cell lines and tumors. Anticancer res, 12, 559-63.

De S (2012). Retrospective analysis of lung function abnormalities of Bhopal gas tragedy affected population. Indian J Med Res, 135, 193.

De S (2013). Annual change in spirometric parameters among patients affected in Bhopal gas disaster: a retrospective observational study. Lung India, 30, 103.

Dhe-Paganon S, Syeda F, Park L (2011). DNA methyl transferase 1: regulatory mechanisms and implications in health and disease. Int J Biochem Mol Biol, $2,58$.

Dikshit RP, Kanhere S (1999). Cancer patterns of lung, oropharynx and oral cavity cancer in relation to gas exposure at Bhopal. Cancer Causes \& Control, 10, 627-36.

Ennever FK, Rosenkranz HS (1987). Evaluating the potential for genotoxic carcinogenicity of methyl isocyanate. Toxicol Appl Pharmacol, 91, 502-5.

Finkelstein JD (1990). Methionine metabolism in mammals. $J$ Nutri Biochem, 1, 228-237.

Fraga MF, Ballestar E, Paz MF, et al (2005). Epigenetic differences arise during the lifetime of monozygotic twins. Pro Nat Aca Sci USA, 102, 10604-9.

Friesner RA, Banks JL, Murphy RB, et al (2004). Glide: a new approach for rapid, accurate docking and scoring. 1. Method and assessment of docking accuracy. J Med Chem, 47, 1739-49.

Friesner RA, Murphy RB, Repasky MP, et al (2006). Extra precision glide: docking and scoring incorporating a model of hydrophobic enclosure for protein-ligand complexes. $J$ Med Chem, 49, 6177-96.

Gassert T, Mackenzie C, Muir KM, et al (1986). Long term pathology of lung, eye, and other organs following acute exposure of rats to methyl isocyanate. Lancet, 2, 1403.

Greenwood JR, Calkins D, Sullivan AP, et al (2010). Towards the comprehensive, rapid, and accurate prediction of the favorable tautomeric states of drug-like molecules in aqueous solution. J Computer-aided Mol Design, 24, 591604.

Guo JU, Su Y, Shin JH, et al (2014). Distribution, recognition and regulation of non-CpG methylation in the adult mammalian brain. Nature Neurosci, 17, 215-222.

Halgren TA, Murphy RB, Friesner RA, et al (2004). Glide: a new approach for rapid, accurate docking and scoring. 2. Enrichment factors in database screening. J Med Chem, 47, 1750-9.

Hariom P, Mishra PK (2011). Repercussion of isocyanates exposure on different cellular proteins in human pulmonary arterial endothelial cells. Int J Res Chem Env, 1, 95-100.

Hariom P, Raghuram GV, Jain D, et al (2011). Cell cycle deregulation by methyl isocyanate: implications in liver carcinogenesis. Environ Toxicol, 1-14.

Heard E, Martienssen RA (2014). Transgenerational epigenetic inheritance: myths and mechanisms. Cell, 157, 95-109.

Hermann A, Goyal R, Jeltsch A (2004). The DNMT1 DNA-(cytosine-C5)-methyltransferase methylates DNA processively with high preference for hemimethylated target sites. J Biol Chem, 279, 48350-9.

Hou L, Zhang X, Wang D, et al (2011). Environmental chemical exposures and human epigenetics. Int J Epi, 154.

HSFS (2002). Methyl isocyanate. RTK 1270, Department of Health and Senior Services, Hazardous substance fact sheet, New Jersey.

Irwin JJ, Shoichet BK (2005). ZINC--a free database of commercially available compounds for virtual screening. $J$ Chem Inf Model, 45, 177-82.

Jacobson MP, Pincus DL, Rapp CS, et al (2004). A hierarchical approach to all atom protein loop prediction. Proteins: Structure, Function, and Bioinformatics, 55, 351-67.

Jeltsch A, Jurkowska RZ (2014). New concepts in DNA methylation. Trends Biochem Sci, 39, 310-8.

Jiang Q, Yu YC, Ding XJ, et al (2014). Bioinformatics analysis reveals significant genes and pathways to target for oral squamous cell carcinoma. Asian Pac J Cancer Prev, 15, 2273-8.

Jones PA, Martienssen R (2005). A blueprint for a human epigenome project: the AACR human epigenome workshop. Cancer Res, 65, 11241-6.

Jurkowska RZ, Jurkowski TP, Jeltsch A (2011).Structure and function of mammalian DNA methyltransferases. 
Chembiochem, 12, 206-22.

Karol MH, Taskar S, Gangal S, et al (1987). The antibody response to methyl isocyanate: experimental and clinical findings. Environ Health Perspectives, 72, 169.

Khamkar T, Abhyankar M, Tendulkar G, et al (2013). In silico molecular docking of marine drugs against cancer proteins. Adv Chem Sci, 2, 24-28.

Kilgore JA, Du X, Melito L, et al (2013). Identification of DNMT1 selective antagonists using a novel scintillation proximity assay. $J$ Biol Chem, 288, 19673-84.

Leonhardt H, Page AW, Weier H-U, et al (1992). A targeting sequence directs DNA methyltransferase to sites of DNA replication in mammalian nuclei. Cell, 71, 865-73.

Li E, Bestor TH, Jaenisch R (1992). Targeted mutation of the DNA methyltransferase gene results in embryonic lethality. Cell, 69, 915-26.

Lu SC (2000). S-adenosylmethionine. Int J Biochem Cell Biol, 32, 391-5.

Mahdavi M, Mohabatkar H, Keyhanfar M, et al (2012). Linear and conformational B cell epitope prediction of the HER 2 ECD-Subdomain III by in silico methods. Asian Pac J Cancer Prev, 13, 3053-9.

Malla TM, Senthilkumar CS, Sharma NC, et al (2011). Chromosome instability among Bhopal gas tragedy survivors. Am Eur J Toxicol Sci, 3, 245-9.

Miller OJ, Schnedl W, Allen J, et al (1974). 5-Methylcytosine localised in mammalian constitutive heterochromatin. Nature, 251, 636-7.

Mishra PK, Bhargava A, Raghuram GV, et al (2009a). Inflammatory response to isocyanates and onset of genomic instability in cultured human lung fibroblasts. Genet Molecul Res, 8, 129-43.

Mishra PK, Bhargava A, Raghuram GV, et al (2009b). Induction of genomic instability in cultured human colon epithelial cells following exposure to isocyanates. Cell Biol Int, 33, 675-83.

Mishra PK, Raghuram GV,Panwar H, et al (2009c). Mitochondrial oxidative stress elicits chromosomal instability after exposure to isocyanates in human kidney epithelial cells. Free Radic Res, 43, 718-28.

Mortusewicz O, Schermelleh L, Walter J, et al (2005). Recruitment of DNA methyltransferase I to DNA repair sites. Pro Nat Aca Sci USA, 102, 8905-9.

NOAAS (2015). METHYL ISOCYANATE. Chemical Datasheet. Office of Response and Restoration, NOAA's Ocean Service, National Oceanic and Atmospheric Administration, USA. gov. Available from URL: http://cameochemicals.noaa.gov/ chemical/1112. Assessed on 27.7.15

Okano M, Bell DW, Haber DA, et al (1999). DNA methyltransferases DNMT3A and DNMT3B are essential for de novo methylation and mammalian development. Cell, 99, 247-57.

PDB (2014a) 3PTA. Protein Data Bank. Available at http:// www.rcsb.org/pdb/explore/explore.do?structureId=3PTA. Assessed on 16.9. 2014.

PDB (2014b) 3SWR. Protein Data Bank. Available at http:// www.rcsb.org/pdb/explore/explore.do?structureId=3SWR. Assessed on 21. 9. 2014.

PDB (2014c) 3EPZ. Protein Data Bank. Available at http:// www.rcsb.org/pdb/explore/explore.do?structureId=3EPZ. Assessed on 10.10.2014

PDB (2014d) 4IEJ. Protein Data Bank. Available at http://www. rcsb.org/pdb/explore/explore.do?structureId=4IEJ.Assessed on 21. 10. 2014

Pradhan M, Esteve P-O, Chin HG, et al (2008). CXXC domain of human DNMT1 is essential for enzymatic activity. Biochem, 47, 10000-9.
Qin W, Leonhardt H, Spada F (2011). Usp7 and Uhrf1 control ubiquitination and stability of the maintenance DNA methyltransferase Dnmt1. J Cell Biochem, 112, 439-444.

Raghuram GV, Pathak N, Jain D, et al (2010). Molecular mechanisms of isocyanate induced oncogenic transformation in ovarian epithelial cells. Reproduct Toxicol, 30, 377-86.

Risner LE, Kuntimaddi A, Lokken AA, et al (2013). Functional specificity of CpG DNA-binding CXXC domains in mixed lineage leukemia. J Biol Chem, 288, 29901-10.

Robertson KD (2005). DNA methylation and human disease. Nature Rev Genetics, 6, 597-610.

Rountree MR, Bachman KE, Baylin SB (2000). DNMT1 binds HDAC2 and a new corepressor, DMAP1, to form a complex at replication foci. Nature genetics, 25, 269-77.

Sastry GM, Adzhigirey M, Day T, et al (2013). Protein and ligand preparation: parameters, protocols, and influence on virtual screening enrichments. J Computer-aided Mol Design, 27, 221-34.

Schluckebier G, Kozak M, Bleimling N, et al (1997). Differential binding of Sadenosylmethionine S-adenosylhomocysteine and Sinefungin to the adenine-specific DNAmethyltransferase M. TaqI. J Mol Biol, 265, 56-67.

Schwetz B, Adkins Jr B, Harris M, et al (1987). Methyl isocyanate: reproductive and developmental toxicology studies in Swiss mice. Environ Health Perspectives, 72, 149.

Senthilkumar CS (2012) Bhopal methyl isocyanate affected population and cancer susceptibility: where do we stand now? Asian Pac J Cancer Prev, 13, 5323-5324.

Senthilkumar CS, Akhter S, Malla TM, et al (2015). Increased micronucleus frequency in peripheral blood lymphocytes contributes to cancer risk in the methyl isocyanate-affected population of Bhopal. Asian Pac J Cancer Prev, 16, 44094419.

Senthilkumar CS, Malla TM, Sah NK, et al (2013). Methyl isocyanate exposure and atypical lymphocytes. Int J Occ Environ Med, 4, 167-168.

Senthilkumar CS, Malla TM, Sah NK, et al (2011). Cancer morbidity among methyl isocyanate exposed long-term survivors and their offspring: a hospital-based five year descriptive study (2006-2011) and future directions to predict cancer risk in the affected population. Asian Pac J Cancer Prev, 12, 3443-52.

Senthilkumar CS, Sah NK, Ganesh N (2012). Methyl isocyanate and carcinogenesis: bridgeable gaps in scientific knowledge. Asian Pacific J Cancer Prev, 13, 2429-2435.

Shelley JC, Cholleti A, Frye LL, et al (2007). Epik: a software program for $\mathrm{pK}$ a prediction and protonation state generation for drug-like molecules. J Computer-aided Mol Design, 21, 681-691.

Shivakumar D, Williams J, Wu Y, et al (2010). Prediction of absolute solvation free energies using molecular dynamics free energy perturbation and the OPLS force field. J Chem Theory Comput, 6, 1509-19.

Shrivastava R, Punde RP, Deshpande S, et al (2010). Molecular characterization and bioinformatics approach of tuberculosis infection prevalent in methyl isocyanate affected population in Bhopal. Pharmacologyonline, 3, 757-767.

Shrivastava R, Yasir M, Tripathi MK, et al (2013). In silico interaction of methyl isocyanate with immune protein responsible for Mycobacterium tuberculosis infection using molecular docking. Toxicol Ind Health, 0748233713498447.

Song CQ, Zhang JH, Shi JC, et al (2014). Bioinformatic Prediction of SNPs within miRNA Binding Sites of Inflammatory Genes Associated with Gastric Cancer. Asian Pac J Cancer Prev, 15, 937-943.

Song J, Teplova M, Ishibe-Murakami S, et al (2012). Structurebased mechanistic insights into DNMT1-mediated 


\section{Inbesat Khan et al}

maintenance DNA methylation. Science, 335, 709-712.

Stringer R, Labunska I, Brigden K, et al (2002). Chemical stockpiles at union carbide india limited in bhopal: an investigation. greenpeace research laboratories. technical note 12/2002. november 2002. ISBN 90, 73361-80.

Tice RR, Luke CA, Shelby MD (1987) Methyl isocyanate: an evaluation of in vivo cytogenetic activity. Environ mutagenesis, 9, 37-58.

Tripathi MK, Yasir M, Gurjar VS, et al (2015). Insights from the molecular docking of hydrolytic products of methyl isocyanate (MIC) to inhibition of human immune proteins. Interdisciplinary Sciences: Computational Life Sciences, 1-8.

Vandenplas O, Malo J-L, Saetta M, et al (1993). Occupational asthma and extrinsic alveolitis due to isocyanates: current status and perspectives. British J Ind Med, 50, 213.

Wang DG, Chen G, Wen XY, et al (2015). Identification of Biomarkers for Diagnosis of Gastric Cancer by Bioinformatics. Asian Pac J Cancer Prev, 16, 1361-5.

Wang Y, Yan L (2015). Analysis of molecular pathways in pancreatic ductal adenocarcinomas with a bioinformatics approach. Asian Pac J Cancer Prev, 16, 2561-7.

Wu BL, Luo LW, Li CQ, et al (2013). Comprehensive bioinformation analysis of the MRNA profile of fascin knockdown in esophageal squamous cell carcinoma. Asian Pac J Cancer Prev, 14, 7221-27.

Zhuo WL, Zhang L, Xie QC, et al (2014). Identifying Differentially Expressed Genes and Screening Small Molecule Drugs for Lapatinib-resistance of Breast Cancer by a Bioinformatics Strategy. Asian Pac J Cancer Prev, 15, 10847-53. 